AperTO - Archivio Istituzionale Open Access dell'Università di Torino

\title{
EARLY SURGERY AND SURVIVAL OF PATIENTS WITH ANAPLASTIC THYROID CARCINOMA: ANALYSIS OF A CASE SERIES REFERRED TO A SINGLE INSTITUTION BETWEEN 1999 - 2012.
}

\section{This is the author's manuscript}

Original Citation:

Availability:

This version is available http://hdl.handle.net/2318/149935

since

Published version:

DOI:10.1089/thy.2014.0004

Terms of use:

Open Access

Anyone can freely access the full text of works made available as "Open Access". Works made available under a Creative Commons license can be used according to the terms and conditions of said license. Use of all other works requires consent of the right holder (author or publisher) if not exempted from copyright protection by the applicable law. 
This is the author's final version of the contribution published as:

Brignardello E1; Palestini N; Felicetti F; Castiglione A; Piovesan A; Gallo M; Freddi M; Ricardi U; Gasparri G; Ciccone G; Arvat E; Boccuzzi G.. EARLY SURGERY AND SURVIVAL OF PATIENTS WITH ANAPLASTIC THYROID CARCINOMA: ANALYSIS OF A CASE SERIES REFERRED TO A SINGLE INSTITUTION BETWEEN 1999 - 2012.. THYROID. 24 (11) pp: 1600-1606.

DOI: $10.1089 /$ thy.2014.0004

The publisher's version is available at:

http://online.liebertpub.com/doi/abs/10.1089/thy.2014.0004

When citing, please refer to the published version.

Link to this full text:

http://hdl.handle.net/2318/149935 


\section{Early Surgery and Survival of Patients with Anaplastic Thyroid Carcinoma: Analysis of a Case Series Referred to a Single Institution Between 1999 and 2012}

Brignardello Enrico, Palestini Nicola, Felicetti Francesco, Castiglione Anna, Piovesan Alessandro, Gallo Marco, Freddi Milena, Ricardi Umberto, Gasparri Guido, Ciccone Giovannino, Arvat Emanuela, and Boccuzzi Giuseppe.

\section{ABSTRACT}

Background: Extensive resection of the tumor has been associated with better survival of anaplastic thyroid carcinoma (ATC) patients. However, surgery is not the rule for ATC patients with distant metastases at the time of diagnosis (stage IV-C), regardless of tumor resectability. The aim of this work was to explore the potential role of surgery in ATC patients, including those in stage IV-C.

Methods: We considered all the consecutive ATC patients referred to our institution from June 1999 to July 2012. Patients with stage IV-A incidentally discovered ATC were excluded because of their better prognosis. All patients eligible for surgery at the time of diagnosis were first operated with the intent to obtain a macroscopically complete resection (R0, R1), or a R2 resection with minimal macroscopical residual tumor. These operations were defined as "maximal debulking," whereas operations that did not achieve this goal were defined as "partial debulking." After surgery, almost all patients received adjuvant chemotherapy, associated to radiotherapy in more than $50 \%$ of patients.

Results: There were 55 eligible patients ( 34 women; median age 73.15 years). Thirty-one patients had distant metastases (stage IV-C). The median overall survival was 5.55 months [Cl 4.94-6.60], with no difference according to stage. "Maximal debulking" was obtained in $70.73 \%$ of operated patients as a first modality and resulted associated with better survival than "partial debulking" (6.57 months [Cl 5.52-12.09] vs. 3.25 months [ $\mathrm{Cl} 0.66-4.80]$ ), without any difference between stage IV-B and IV-C patients. Furthermore, $21 \%$ of patients submitted to "maximal debulking" died secondary to local progression of the tumor, whereas this was the case for $69 \%$ of patients treated with "partial debulking" or not operated at all.

Conclusions: Early "maximal debulking," followed by adjuvant therapy, can improve the survival and ameliorate the quality of residual life preventing the risk of suffocation. This effect is also observed in patients with distant metastasis at diagnosis and treated with this approach: they have an outcome similar to that observed in stage IV-B patients. We thus suggest that surgery may be considered in the management of all ATC patients, and should not be restricted $a$ priori to stages IV-A and IV-B.

\section{Introduction}

Anaplastic thyroid carcinoma (ATC) is a very rare disease and also one of the most aggressive human malignant tumors, with a median survival of $<6$ months in most of the published data (1-5). ATC is characterized by both a very fast local growth and a distant spread. Indeed, most patients present with a rapidly enlarging neck mass, often associated with progressive locoregional symptoms such as vocal cord paralysis, dyspnea, and dysphagia arising from infiltration of the surrounding organs (larynx, trachea, esophagus, muscles, carotid arteries, and other blood vessels). Moreover, about $50 \%$ of patients have distant metastases at diagnosis (6). An integrated approach to ATC patients is therefore required to treat both locoregional disease and distant metastases effectively, even if occult.

Due to its rarity, there is no standard therapy for ATC. In selected patients, a multimodal approach including surgery, radiation therapy, and chemotherapy has been proposed to improve survival $(5,7-9)$. Nevertheless, ATC patients almost invariably have a grim prognosis $(5,10)$. 
Several studies have reported that extensive (even if incomplete) resection of the tumor is associated with better survival $(3,8,11-14)$. However, surgery is not the rule for ATC patients with distant metastases at the time of diagnosis (stage IV-C), regardless of tumor resectability, as clearly stated by the available guidelines (15) and by recent studies focusing on this topic $(8,9)$.

This position seems coherent with the dismal median survival time of ATC patients in stage IV-C, ranging between 1.7 months $(2)$ and 3.0 months $(5,16)$, with a one-year survival of approximately $\leq 8 \%(16,17)$. Indeed, the local control of tumor progression is a leading component in treating ATC patients, and it is best obtained by surgery $(8,11,14,17)$.

At our institution, ATC patients are usually treated by a multimodal approach that includes surgery (whenever it is possible and not otherwise contraindicated), regardless of the presence or absence of distant metastases. Our aim is to describe the outcome of our case series and to explore the potential effect of early surgery on survival, including ATC patients in stage IV-C.

\section{Patients and Methods}

\section{Patients}

We collected all the consecutive cases of ATC referred to the Oncological Endocrinology Unit of Città della Salute e della Scienza Hospital (Turin, Italy) between June 1999 and July 2012. Based on the retrospective design of the study, Institutional Review Board approval was not required according to Italian law.

The diagnosis of ATC was obtained by cytological examination of specimens following fine-needle aspiration, and was confirmed by histologic examination in all patients who underwent surgery.

In all cases, examination of the specimens was performed at the pathology department of our hospital. To define the diagnosis of ATC, the smears were examined by two different pathologists with proven experience in the field of thyroid cancer.

The stage of all cases was reported according to the seventh edition of the AJCC Cancer Staging Manual (18). According to this manual, intrathyroidal ATC without distant metastases is classified as stage IV-A while extrathyroidal ATC without distant metastases is stage IV-B. The presence of any distant metastasis leads to categorization as stage IV-C. Patients with incidentally discovered stage IV-A ATC were excluded from statistical analysis because of their better prognosis (19).

\section{Treatment protocol}

Patients were classified as eligible or not for surgery by a multidisciplinary team involving surgeons, endocrine-oncologists, and radiation therapists. The decision was made taking into account the local extent of disease (in terms of adjacent structures involvement) as well as the patient's age and overall clinical condition. Cross-sectional imaging studies, fiber-optic laryngoscopy, and, in selected cases, tracheo- and/or esophagoscopy provided preoperative assessment of tumor involvement with the visceral compartment, adjacent vascular structures, and the posterior paraspinous structures. Usually, patients were considered not eligible for surgery in the overt presence of visceral structures (hypopharynx, esophagus, larynx, and/or trachea) infiltration, involvement of vascular structures of the mediastinum, or posterior tumor extension with infiltration of the prevertebral fascia and paraspinous muscles.

Furthermore, all the patients were staged for distant metastasis with a computed tomographic (CT) scan of the neck, chest, and upper abdomen. When clinically indicated, preoperative staging also included a CT scan of the brain and a bone scan. In any case, the presence of distant metastases (stage IV-C) was 
considered a contraindication to surgery only if predictive of a very short life expectancy, due to their number and/or site.

Very old age (80 years or older) represented a contraindication to surgery only if associated with poor general condition.

All patients eligible for surgery were first operated with the intent to obtain a macroscopically complete resection (R0, R1), or a R2 resection with minimal macroscopical residual tumor adherent to vital structures (pharynx, esophagus, larynx, or trachea) (14) (Fig. 1). If this result was obtained, operations were defined as "maximal debulking," whereas operations that did not achieve this goal were defined as "partial debulking."

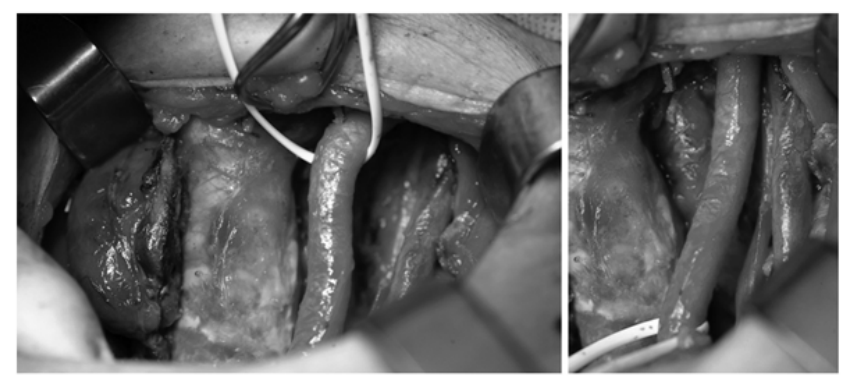

FIG. 1. R2 resection with minimal residual disease ("maximal debulking"): the tumor was resected leaving an area of tracheal infiltration; the elements of left vascular bundle were dissected from the mass; the contralateral normal thyroid lobe has not yet been removed.

This is a retrospective study, and patients were treated over a long time span, thus resulting in an inevitable heterogeneity in the administered adjuvant treatments (Fig. 2). After surgery, almost all patients received an adjuvant treatment usually consisting of (a) 3D-conformal radiotherapy (1.8-2.0 Gy daily fractions, five days a week, up to a planned total dose of 50-54 Gy) combined with radiosensitizing chemotherapy (doxorubicin $20 \mathrm{mg} / \mathrm{m}^{2}+c i s$-platin $20 \mathrm{mg} / \mathrm{m}^{2}$, administered once weekly) for the entire duration of radiotherapy, then doxorubicin $\left(60 \mathrm{mg} / \mathrm{m}^{2}\right)+c i s$-platin $\left(50-60 \mathrm{mg} / \mathrm{m}^{2}\right)$ every three weeks, up to a maximum doxorubicin dose of $550 \mathrm{mg} / \mathrm{m}^{2}$ or until tolerated; (b) chemotherapy only, which consisted of paclitaxel at a weekly dose of $80-120 \mathrm{mg} / \mathrm{m}^{2}$ until tolerated. The "off-label" use of paclitaxel was approved by the Institutional Review Board of the Città della Salute e della Scienza Hospital.

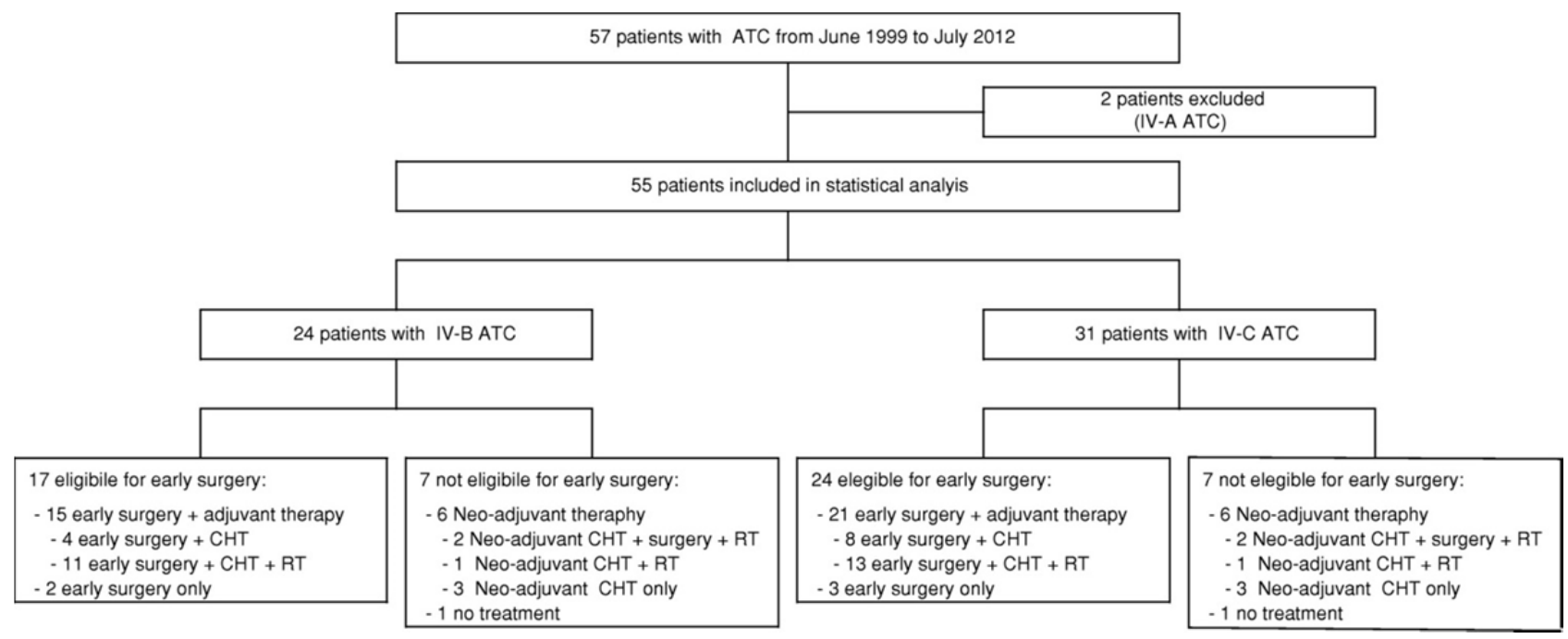

FIG. 2. Study population and treatment modalities.

Patients classified as not eligible for surgery usually received 3D-conformal radiotherapy (1.8-2.0 Gy daily fractions, five days a week, up to a planned total dose of 50-54 Gy) combined with radiosensitizing 
chemotherapy (doxorubicin $20 \mathrm{mg} / \mathrm{m}^{2}+c i s$-platin $20 \mathrm{mg} / \mathrm{m}^{2}$ once weekly) for the entire duration of the radiotherapy, with neo-adjuvant intent. For selected patients, surgery was performed about three weeks after completion of the combined chemoradiotherapy. After surgery, patients received adjuvant chemotherapy with either (a) paclitaxel, at a weekly dose of $80-120 \mathrm{mg} / \mathrm{m}^{2}$ until tolerated, or (b) doxorubicin $\left(60 \mathrm{mg} / \mathrm{m}^{2}\right)+c i s$-platin $\left(50-60 \mathrm{mg} / \mathrm{m}^{2}\right)$ every three weeks, up to a maximum doxorubicin dose of $550 \mathrm{mg} / \mathrm{m}^{2}$ or until tolerated. Patients still not eligible for surgery after the neo-adjuvant treatment continued chemotherapy with weekly paclitaxel or doxorubicin+cis-platin.

In the presence of contraindications to both surgery and radiotherapy, patients were treated with weekly paclitaxel at a dose of $80-120 \mathrm{mg} / \mathrm{m}^{2}$ until tolerated.

Very old patients and/or patients in poor clinical condition received no treatment beyond palliation.

Statistical analysis

Characteristics of the patients are described using medians and interquartile ranges for the continuous variables. Percentage frequencies were used for the categorical variables.

In the whole population, the overall survival (OS), estimated using the Kaplan-Meier method, was defined as the time from cytological diagnosis, or date of surgery when date of cytological diagnosis was not available, until the date of death or the last observation. First, we compared the OS between eligible and noneligible patients for surgery. In order to estimate the effect of "maximal debulking," we then limited the analysis only to eligible patients. We considered as time at risk the elapsed time from the date of surgery until the date of death or the end of the observation. The Cox proportional hazard model was performed to estimate the crude and adjusted hazard ratios (HRs) and confidence intervals (Cls).

Statistical analyses were performed using Stata v11.2 (StataCorp LP, College Station, TX).

\section{Results}

The characteristics of the ATC patients included in this study are shown in Table 1 . There were 34 females and 21 males. Median age at diagnosis was 73.15 years (range 42-92; q1-q3 64.61-79.19). Forty patients (74.07\%) had a previous diagnosis of nodular goiter. Almost all patients (85.5\%) had normal thyroid function, but six patients (11.11\%) had a previous history of hyperthyroidism (toxic multinodular goiter in all these patients). Thirty-one patients (56.4\%) had distant metastases at the time of cancer diagnosis. The tumor size was rather similar in stage IV-B and stage IV-C patients (M $\pm S D 7.76 \pm 2.04 \mathrm{~cm}$ vs. $6.39 \pm 2.77 \mathrm{~cm}$ ), and it was similar in operated and not operated patients ( $M \pm S D 6.64 \pm 2.63 \mathrm{~cm}$ vs. $7.48 \pm 2.69 \mathrm{~cm}$ ).

Table 1. Patients Characteristics

$\begin{array}{lcc} & \text { N } & \% \\ \text { Sex } & & \\ \text { Female } & 34 & 61.82 \\ \text { Male } & 21 & 38.18 \\ \text { Age-median [q1-q3] }^{*} & 73.15 & \text { [64.61-79.19] } \\ \text { Thyroid function }^{*} & & \\ \text { Hyperthyroidism }^{\text {Normal }} & 6 & 10.91 \\ \text { Stage IV-C }^{*} & 48 & 89.09 \\ \text { Goiter }^{*} \text { Fine-needle aspiration }^{*} & 31 & 56.36 \\ \text { Treatment strategy }^{*} & 40 & 74.07 \\ & 43 & 79.63\end{array}$




$\begin{array}{lcc} & \text { N } & \text { \% } \\ \text { Eligible for surgery } & 41 & 74.55 \\ \text { Early surgery alone } & 5 & 9.09 \\ \text { Early surgery+CHT } & 12 & 21.82 \\ \text { Early surgery+CHT+RT } & 24 & 43.64 \\ \text { Not eligible for surgery } & 14 & 25.45 \\ \text { Neo-adjuvant CHT+RT+surgery } & 4 & 7.27 \\ \text { Neo-adjuvant CHT+RT } & 2 & 3.64 \\ \text { Neo-adjuvant CHT only } & 6 & 10.91 \\ \text { No treatment } & 2 & 3.64 \\ \text { Total } & 55 & 100\end{array}$

*One missing for thyroid function, goiter, fine-needle aspiration.

$\mathrm{CHT}$, chemotherapy; RT, radiotherapy.

Treatment modalities are shown in Figure 2; two patients (one stage IV-B, the other stage IV-C) received no treatment other than palliation.

Forty-one patients (74.55\%) were eligible for early surgery. Seven out of 31 stage IV-C patients were judged not eligible for early surgery (Fig. 2), four due to widespread metastases (suggesting a very low life expectancy) and the other three because of the local extent of disease.

As far as stage IV-B patients are concerned, 7 out of 24 were excluded from early surgery (Fig. 2) due to local extent of disease $(n=3)$ or because of their poor clinical condition and/or comorbidities $(n=4)$.

"Maximal debulking" was obtained in 29 cases (11 stage IV-B; 18 stage IV-C), with a macroscopically complete resection of cervical tumor in nine cases (four R0 and five R1 resections), whereas the other 20 were $\mathrm{R} 2$ resections with minimal residual tumor adherent to vital structures.

Survival analysis

The six-month and one-year survival rates were respectively $49.09 \%$ [Cl 35.39-61.42] and $19.70 \%$ [Cl 10.41-31.14], with a median OS time of 5.55 months ([CI 3.94-6.60]; Fig. 3A). We observed no difference in OS according to stage $(p=0.712)$ : in stage IV-B, the six-month and one-year survival rates were $50.00 \%[\mathrm{Cl}$ 29.10-67.76] and 20.83\% [Cl 7.59-38.52] respectively, and in stage IV-C 48.32\% [Cl 30.18-64.41] and $18.82 \%$ ([Cl 7.38-34.29]; Fig. 3B). 


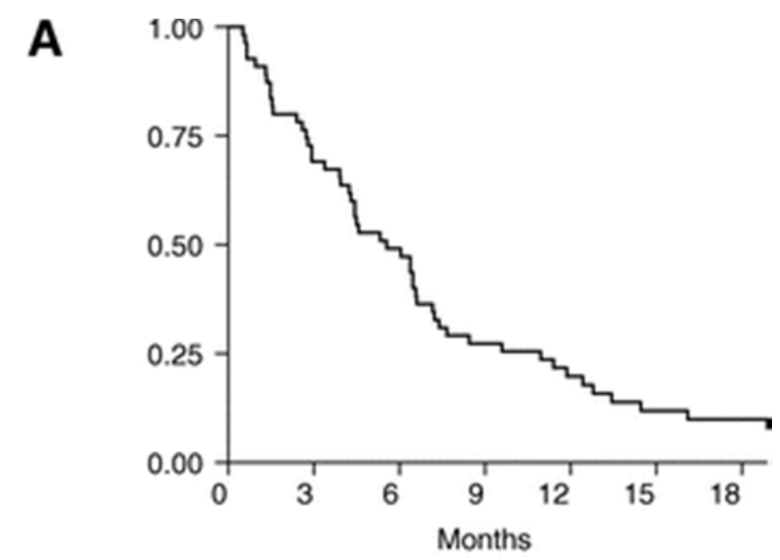

Patients at risk
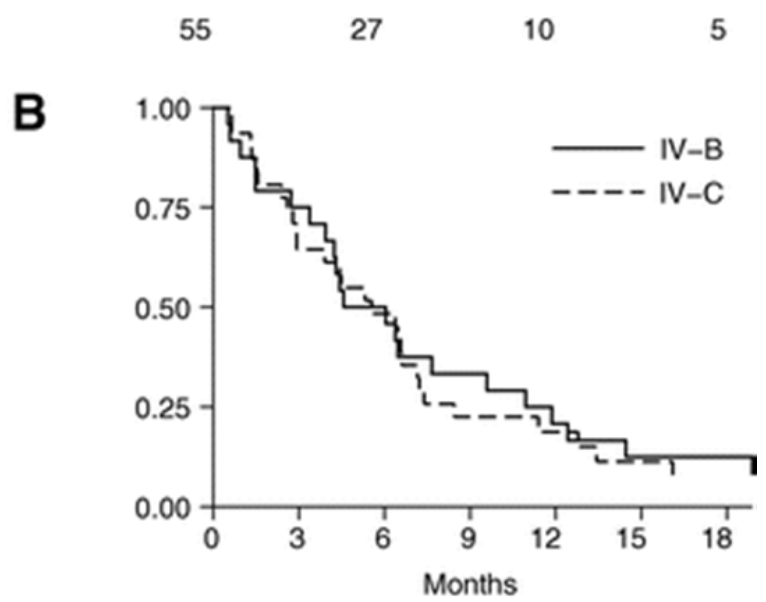

Patients at risk

$\begin{array}{lllll}\text { IV-B } & 24 & 12 & 5 & 3 \\ \text { IV-C } & 31 & 15 & 5 & 2\end{array}$

FIG. 3. Overall survival: (A) all patients; (B) according to the staging.

Patients eligible for early surgery had a longer survival considering both IV-B and IV-C stages together and separately. The median survival times were 6.47 months $[\mathrm{Cl} 4.50-8.44]$ and 1.48 months $[\mathrm{Cl} 0.95-4.24]$ in eligible and noneligible patients respectively (Table 2 ). In patients eligible for early surgery ( $n=41,74.55 \%)$, the "maximal debulking" was associated with a longer survival, even in stage IV-C patients (Fig. 4). In the whole population, the median survival time from surgery was 6.57 months [CI 5.52-12.09] in patients where the "maximal debulking" was successfully performed, and 3.25 months [ $\mathrm{Cl} 0.66-4.80]$ in patients where the surgical procedure was classified as "partial debulking" (Table 3). In stage IV-B and stage IV-C, the median survival time from surgery of patients who underwent "maximal debulking" was 10.94 [Cl 3.9114.45] and 6.50 months [Cl 4.20-12.22] respectively, significantly longer than that observed after "partial debulking" (Table 3). After maximal debulking, the one-year survival was $36.36 \%$ in stage IV-B and $27.77 \%$ in stage IV-C patients. In contrast, no patient was alive one year after "partial debulking," in either stage IVB or IV-C (Fig. 4). 
A

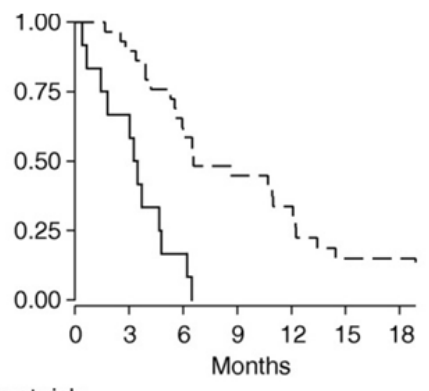

Patients at risk

$\begin{array}{rccc}\text { Partial debulking } 12 & 2 & 0 & 0 \\ \text { Maximal debulking } 29 & 17 & 9 & 4\end{array}$

B

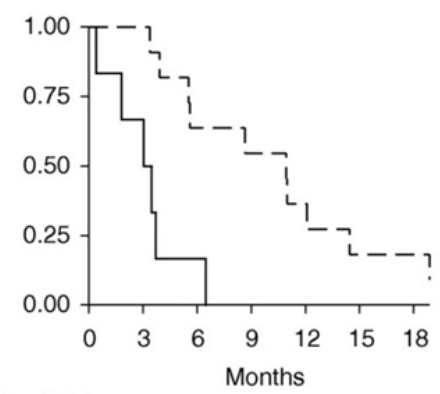

Patients at risk

$\begin{array}{ccccc}\text { Partial debulking } & 6 & 1 & 0 & 0 \\ \text { Maximal debulking } & 11 & 7 & 4 & 2\end{array}$

FIG. 4. Overall survival from surgery according to surgery type: (A) whole population; (B) stage IV-B patients; (C) stage IV-C patients.

Table 2. Median Survival Time from Diagnosis According to Staging and Eligibility for Surgery

N Median time SE $\quad \mathrm{Cl}$

Stage IV-B

Eligible for surgery $\quad 17 \quad 6.37 \quad 1.313 .9411 .86$

$\begin{array}{lllll}\text { Not eligible for surgery } 7 & 1.48 & 0.34 & 0.53 \quad 7.65\end{array}$

$\begin{array}{llllll}\text { Total } & 24 & 4.57 & 1.27 & 3.38 & 9.59\end{array}$

Stage IV-C

$\begin{array}{llllll}\text { Eligible for surgery } \quad 24 & 6.57 & 0.99 & 4.43 & 8.44\end{array}$

$\begin{array}{llllll}\text { Not eligible for surgery } 7 & 1.54 & 0.26 & 0.66 & 2.40\end{array}$

$\begin{array}{llllll}\text { Total } & 31 & 5.55 & 1.13 & 2.92 & 7.16\end{array}$

All

$\begin{array}{llllll}\text { Eligible for surgery } \quad 41 & 6.47 & 0.36 & 4.50 & 8.44\end{array}$

Not eligible for surgery $14 \quad 1.48 \quad 0.120 .95 \quad 4.24$

$\begin{array}{llllll}\text { Total } & 55 & 5.55 & 1.03 & 3.94 & 6.60\end{array}$

$\mathrm{SE}$, standard error; $\mathrm{Cl}$, confidence interval.

Table 3. Median Survival Time from Surgery According to Surgery Type in Patients Eligible for Surgery $(N=41)$

\section{N Median time SE $\mathrm{Cl}$}

Stage IV-B

Maximal debulking $11 \quad 10.94 \quad 2.963 .9114 .45$

Partial debulking $\quad 6 \quad 3.02 \quad 1.030 .35$

$\begin{array}{llllll}\text { Total } & 17 & 5.58 & 1.76 & 3.38 & 10.97\end{array}$

Stage IV-C 


\begin{tabular}{lcccccc} 
& \multicolumn{3}{c}{ N } & Median time & SE & \multicolumn{1}{c}{ Cl } \\
Maximal debulking & 18 & 6.50 & 0.55 & 4.20 & 12.22 \\
Partial debulking & 6 & 3.25 & 1.97 & 0.66 & \\
Total & 24 & 5.95 & 0.86 & 3.91 & 6.57 \\
All & & & & & \\
Maximal debulking & 29 & 6.57 & 1.79 & 5.52 & 12.09 \\
Partial debulking & 12 & 3.25 & 0.40 & 0.66 & 4.80 \\
Total & 41 & 5.95 & 0.59 & 3.91 & 6.57
\end{tabular}

Multivariate analysis confirmed the beneficial effect of "maximal debulking" on survival $(\mathrm{HR}=5.36[\mathrm{Cl} 2.34-$ $12.30], p<0.001)$, whereas no influence was demonstrated for stage at diagnosis or for radiation therapy (Table 4).

Table 4. Crude and Adjusted Hazard Ratio in Patients Eligible for Surgery ( $N=41)$

\begin{tabular}{|c|c|c|c|c|c|c|}
\hline & \multicolumn{3}{|c|}{ Univariate } & \multicolumn{3}{|c|}{ Multivariate } \\
\hline & $H R$ & $\mathrm{Cl}$ & $\mathrm{p}$-Value & $H R$ & $\mathrm{Cl}$ & p-Value \\
\hline \multicolumn{7}{|l|}{ Staging } \\
\hline IV-B & 1.00 & & & & & \\
\hline IV-C & 1.040 .55 & 1.99 & 0.900 & 1.090 .57 & 72.09 & 0.800 \\
\hline \multicolumn{7}{|l|}{ Surgery type } \\
\hline Maximal debulking & 1.00 & & & 1.00 & & \\
\hline Partial debulking & 5.332 .33 & 12.19 & $<0.001$ & 5.362 .34 & 412.30 & $<0.001$ \\
\hline \multicolumn{7}{|l|}{ Radiotherapy } \\
\hline No & 1.00 & & & 1.00 & & \\
\hline Yes & 0.750 .39 & 1.44 & 0.389 & 0.770 .40 & 1.47 & 0.427 \\
\hline
\end{tabular}

$H R$, hazard ratio.

Only 6 out of 29 patients (21\%) submitted to "maximal debulking" died secondary to local progression of the tumor, whereas this was the case for the majority (69\%) of patients treated with "partial debulking" or not operated at all. Patients who did not die due to local progression of the tumor showed a progression of distant metastases (mainly in the lung) and/or progressive cancer cachexia.

Treatment-related morbidity

Sternothyroid muscles were routinely excised with the tumor, and in case of "maximal debulking," resection of other adjacent involved structures was often required: sternohyoid muscles (nine cases); ipsilateral sternocleidomastoid muscle (partial resection in three patients); ipsilateral internal jugular vein (10 cases); ipsilateral recurrent laryngeal nerve (RLN), still functioning but encased by the tumor (seven cases); ipsilateral vagus or phrenic nerve (two and one cases respectively); muscular layer of esophagus and/or pharynx (six cases). In three patients, tumor extension in the upper mediastinum required an enlarged approach through a partial sternotomy.

After "maximal debulking," incidental RLN injury was observed in two patients; unfortunately, in one of them, the contralateral RLN was already paralyzed due to tumor infiltration, and the resulting bilateral paralysis required tracheostomy. Nine patients experienced postoperative hypocalcemia, and two further patients (alive and still requiring calcium and vitamin D six months after surgery) were considered to have permanent hypoparathyroidism. Surgical morbidity also included: one intraoperative hemorrhage (requiring blood transfusion) from the left brachiocephalic vein, controlled after partial sternotomy by clamping and suture; one episode of immediate postoperative respiratory insufficiency (due to laryngeal edema and monolateral RLN paralysis) that resolved after reintubation and a 24-hour stay in the intensive 
care unit; one case of deep venous thrombosis with pulmonary embolism that required placement of an inferior vena cava filter; and one wound seroma, which resolved after percutaneous aspiration.

Aerodigestive tract involvement required tracheostomy in a further four cases (two after "maximal debulking"), whereas in two patients, a "partial debulking" ended with a gastrostomy. Postoperative inhospital stay ranged from 2 to 16 days (median 5 days) after "maximal debulking," and from 4 to 45 days (median 10 days) following a "partial debulking."

As expected, neutropenia was observed in most patients treated with cis-platin+doxorubicin, requiring a dose reduction in $39 \%$ of cases. In nine patients, we observed self-limited reactions to paclitaxel, which did not prevent therapy continuing. One patient unfortunately died from central venous catheter sepsis.

Radiation therapy caused symptomatic esophagitis in 20 out of 30 patients, with inadequate oral caloric/fluid intake requiring temporary parenteral nutrition or endoscopic gastrostomy in eight and two cases respectively.

\section{Discussion}

ATC patients eligible for surgery at the time of diagnosis were first operated and subsequently received adjuvant treatment. These patients had a better outcome than those excluded from early surgery, but this comparison is of limited interest, likely reflecting a strong selection bias in favor of the surgical subgroup. Indeed, patients who were first operated could have had a better prognosis due to a less extensive disease and/or a better performance status. Among patients being operated as first modality, those receiving a successful "maximal debulking" had a survival that was about twice as long as that observed after "partial debulking." This difference could be due to a lesser extent of the disease in patients for whom it was possible to obtain "maximal debulking." However, when we considered ATC patients in stage IV-C, we observed that after "maximal debulking," not only the median survival time but also the lower limit of the confidence intervals were similar to those of stage IV-B patients who received the same treatment, and longer than those reported in the literature $(2,5,16,17)$. Moreover, after "maximal debulking," the one-year survival was similar in stage IV-B and IV-C patients ( $36.36 \%$ and $27.77 \%$ respectively), whereas no patient submitted to "partial debulking" was alive one year after surgery. It is unlikely that this result is completely due to a selection bias enriching the stage IV-C surgery group with patients with less advanced metastatic disease. Indeed, only 4 out of 31 stage IV-C patients were excluded from early surgery because of widespread metastases that suggested a very low life expectancy. The better survival associated with early "maximal debulking" (that overall we achieved in 11/24 stage IV-B and 18/31 stage IV-C patients) may be explained by a reduced risk of dying from local progression of the tumor, which is the most dramatic and rapidly fatal evolution of ATC. In our series, post-surgery radiation therapy seems to have less impact on survival (Table 4). Anyway, this result should not be overstated, since the majority of our patients had received 3D conformal radiotherapy at doses $\langle 55 \mathrm{~Gy}$, whereas recently published studies highlighted that better results are achievable using intensity modulated radiotherapy (IMRT) at doses >60 Gy $(15,20)$.

The effect of chemotherapy was not evaluable, since it was administered to almost all patients.

These observations have given rise to some considerations. ATC is one of the most difficult malignancies to treat. We are aware that the difference in survival that could be obtained by any aggressive managementincluding early "maximal debulking" - is often small, perhaps of limited clinical significance (5), and possibly cancelled out by the morbidity consequent to surgery and the side effects of chemo- and radiotherapy. Nevertheless, our data show that, in selected ATC patients, early "maximal debulking" followed by adjuvant chemo/radiotherapy has an acceptable morbidity, can improve survival, and may ameliorate the quality of residual life, preventing the risk of death by suffocation. 
Furthermore, our data show that this approach is feasible as well as useful for a high proportion of ATC patients with distant metastases. It should be emphasized that even if the prognosis of these patients remains poor, the local control of disease (that we obtained with an acceptable morbidity) is an important goal within the context of palliative interventions. However, surgical options are not usually taken into account for ATC patients in stage IV-C, regardless of tumor resectability.

A definite conclusion about the effectiveness of different therapeutic approaches for ATC is clearly outside the possibilities of observational studies such as this one. However, on the basis of these results, we suggest that surgery may be considered in the management of all ATC patients and not restricted $a$ priori to stages IV-A and IV-B.

\section{References}

1. SA Hundahl, ID Fleming, AM Fremgen, HR Menck 1998 A National Cancer Data Base report on 53,856 cases of thyroid carcinoma treated in the U.S., 1985-1995. Cancer 83:2638-2648.

2. B Mclver, ID Hay, DF Giuffrida, CE Dvorak, CS Grant, GB Thompson, JA van Heerden, JR Goellner 2001 Anaplastic thyroid carcinoma: a 50-year experience at a single institution. Surgery 130:1028-1034.

3. E Kebebew, FS Greenspan, OH Clark, KA Woeber, A McMillan 2005 Anaplastic thyroid carcinoma. Treatment outcome and prognostic factors. Cancer 103:1330-1335.

4. RC Smallridge, JA Copland 2010 Anaplastic thyroid carcinoma: pathogenesis and emerging therapies. Clin Oncol (R Coll Radiol) 22:486-497.

5. MR Haymart, M Banerjee, H Yin, F Worden, JJ Griggs 2013 Marginal treatment benefit in anaplastic thyroid cancer. Cancer 119:3133-3139.

6. C Are, AR Shaha 2006 Anaplastic thyroid carcinoma: biology, pathogenesis, prognostic factors, and treatment approaches. Ann Surg Oncol 13:453-464.

7. D Pudney, H Lau, JD Ruether, V Falck 2007 Clinical experience of the multimodality management of anaplastic thyroid cancer and literature review. Thyroid 17:1243-1250.

8. K Ito, T Hanamura, K Murayama, T Okada, T Watanabe, M Harada, T Ito, H Koyama, T Kanai, K Maeno, Y Mochizuki, J Amano 2012 Multimodality therapeutic outcomes in anaplastic thyroid carcinoma: improved survival in subgroups of patients with localized primary tumors. Head Neck 34:230-237.

9. RC Smallridge 2012 Approach to the patient with anaplastic thyroid carcinoma. J Clin Endocrinol Metab 97:2566-2572.

10. AT Swaak-Kragten, JH de Wilt, PI Schmitz, M Bontenbal, PC Levendag 2009 Multimodality treatment for anaplastic thyroid carcinoma-treatment outcome in 75 patients. Radiother Oncol 92:100-104.

11. PI Haigh, PH Ituarte, HS Wu, PA Treseler, MD Posner, JM Quivey, QY Duh, OH Clark 2001 Completely resected anaplastic thyroid carcinoma combined with adjuvant chemotherapy and irradiation is associated with prolonged survival. Cancer 91:2335-2342.

12. A Machens, R Hinze, C Lautenschläger, O Thomusch, J Dunst, H Dralle 2001 Extended surgery and early postoperative radiotherapy for undifferentiated thyroid carcinoma. Thyroid 11:373-380.

13. K Sugino, K Ito, T Mimura, M Nagahama, N Fukunari, A Kubo, H Iwasaki, K Ito 2002 The important role of operations in the management of anaplastic thyroid carcinoma. Surgery 131:245-248.

14. E Brignardello, M Gallo, I Baldi, N Palestini, A Piovesan, E Grossi, G Ciccone, G Boccuzzi 2007 Anaplastic thyroid carcinoma: clinical outcome of 30 consecutive patients referred to a single institution in the past 5 years. Eur J Endocrinol 156:425-430.

15. RC Smallridge, KB Ain, SL Asa, KC Bible, JD Brierley, KD Burman, E Kebebew, NY Lee, YE Nikiforov, MS Rosenthal, MH Shah, AR Shaha, RM Tuttle 2012 American Thyroid Association Anaplastic Thyroid Cancer Guidelines Taskforce. American Thyroid Association guidelines for management of patients with anaplastic thyroid cancer. Thyroid 22:1104-1139.

16. J Chen, JD Tward, DC Shrieve, YJ Hitchcock 2008 Surgery and radiotherapy improves survival in patients with anaplastic thyroid carcinoma: analysis of the surveillance, epidemiology, and end results 1983-2002. Am J Clin Oncol 31:460-464.

17. J Akaishi, K Sugino, W Kitagawa, M Nagahama, K Kameyama, K Shimizu, K Ito, K Ito 2011 Prognostic factors and treatment outcomes of 100 cases of anaplastic thyroid carcinoma. Thyroid 21:1183-1189. 
18. SB Edge, DR Byrd, CC Compton, AG Fritz, FL Greene, A Trotti (eds) 2010 AJCC Cancer Staging Manual. Seventh edition. Springer, New York, NY, pp 87-96.

19. I Sugitani, A Miyauchi, K Sugino, T Okamoto, A Yoshida, S Suzuki 2012 Prognostic factors and treatment outcomes for anaplastic thyroid carcinoma: ATC Research Consortium of Japan cohort study of 677 patients. World J Surg 36:1247-1254.

20. EJ Sherman, SH Lim, AL Ho, RA Ghossein, MG Fury, AR Shaha, M Rivera, O Lin, S Wolden, NY Lee, DG Pfister 2011 Concurrent doxorubicin and radiotherapy for anaplastic thyroid cancer: a critical re-evaluation including uniform pathologic review. Radiother Oncol 101:425-430. 